\title{
CLASSIFICAÇÃO E NORMAS DE SEGURANÇA PARAA PRÁTICA DE EDUCAÇÃO AMBIENTAL NA TRILHA INTERPRETATIVA DO ARROZ, SÍTIO JAQUEIRA AGROECOLOGIA - ALEGRE, ES
}

\author{
CARVALHO, Stephan Lopes ${ }^{1}$ \\ SOUZA, Maurício Novaes ${ }^{2}$ \\ FERRARI, Jéferson Luiz ${ }^{3}$ \\ MEIRA, Ana Cláudia Hebling ${ }^{4}$
}

Recebido em: 2021.01.22 Aprovado em: 2021.04.29 ISSUE DOI: 10.3738/1982.2278.3894

\begin{abstract}
RESUMO: As trilhas ecológicas interpretativas surgem dentro do contexto e abordagem da educação ambiental como um recurso metodológico, ou seja, uma prática ambiental, que visa a transmissão de conhecimentos por meio da percepção, oriunda da visão, olfato e sentimentos, tornando-se uma experiência direta com a realidade de forma interdisciplinar, possibilitando a consciência ambiental dos cidadãos. O Sítio Jaqueira Agroecologia, localizado no município de Alegre, Estado do Espírito Santo, possui grande potencial para a prática da educação ambiental, principalmente através da visitação da Trilha Interpretativa do Arroz. No entanto, vale ressaltar que nas trilhas ecológicas também é essencial que se possuam regras e normas de segurança definidas para permitir aos visitantes condições seguras durante todo percurso. Assim, o objetivo deste trabalho foi classificar a Trilha Interpretativa do Arroz, situada no Sítio Jaqueira Agroecologia localizado no município de Alegre/ES e sugerir a implantação de normas de segurança para a prática da educação ambiental na trilha. Para a normatização da trilha quanto a inserção de placas e a segurança, recorreu-se a ABNT, por intermédio da NBR 15505-2:2019. Verificou-se que o trajeto da trilha estudada pode ser considerado seguro e que a sugestão de placa a ser confeccionada representará de modo metódico os ambientes observados durante a visitação.
\end{abstract}

Palavras-chaves: Educação Não formal; Trilhas ecológicas; Turismo de aventura.

\section{CLASSIFICATION AND SAFETY STANDARDS FOR THE ENVIRONMENTAL EDUCATION PRACTICE ON THE RICE INTERPRETATIVE TRAIL, SITE JAQUEIRA AGROECOLOGIA - ALEGRE, ES}

\begin{abstract}
SUMMARY: The interpretive ecological trails appear within the context and approach of environmental education as a methodological resource, that is, an environmental practice, which aims to transmit knowledge through perception, derived from sight, smell and feelings, becoming a direct experience with the reality in an interdisciplinary way, making citizens' environmental awareness possible. The Jaqueira Agroecology Site, located in the municipality of Alegre, State of Espírito Santo, has great potential for the practice of environmental education, mainly through the visitation of the interpretive trail of Rice. However, it is worth mentioning that on ecological trails it is also essential to have safety rules and norms defined to allow visitors safe conditions throughout the route. The objective of this work was to classify the interpretive trail of Rice, located in the Jaqueira Agroecology Site located in the city of Alegre / ES and to suggest the implementation of safety standards for the practice of environmental education on the trail. For the standardization of the trail regarding the insertion of plates and safety, ABNT was used, through NBR 15505-2: 2019. It was verified that the path of the studied trail can be considered safe and that the suggestion of a sign to be made will represent in a methodical way the environments observed during the visitation.
\end{abstract}

Keywords: Non-formal education; Ecological trails; Adventure tourism.

\footnotetext{
${ }^{1}$ MSc. pelo Programa de Pós-Graduação em Agroecologia do Instituto Federal do Espírito Santo - Campus de Alegre, Caixa Postal 47, CEP: 29500-000, Alegre-ES. E-mail: stephan.carvalho@ifes.edu.br

${ }^{2}$ DSc. Professor do Instituto Federal do Espírito Santo - Campus de Alegre, Caixa Postal 47, CEP: 29500-000, Alegre-ES. E-mail: mauricios.novaes@ifes.edu.br

${ }^{3}$ DSc. Professor do Instituto Federal do Espírito Santo - Campus de Alegre, Caixa Postal 47, CEP: 29500-000, Alegre-ES. E-mail: ferrarijl@ifes.edu.br

${ }^{4}$ DSc. Professor do Instituto Federal do Espírito Santo - Campus de Alegre, Caixa Postal 47, CEP: 29500-000, Alegre-ES. E-mail: anameira2002@yahoo.com.br
} 


\section{INTRODUÇÃO}

Situado no sul do Estado do Espírito Santo, o Sítio Jaqueira Agroecologia, localizado no município de Alegre, segue os princípios da agroecologia buscando formas sustentáveis de uso dos recursos naturais e a adequação à legislação florestal. Além da produção de alimentos agroecológicos, o sítio recebe estudantes e outros públicos para visitas guiadas nas trilhas que mostram além da beleza natural, as práticas agroecológicas praticadas no local (SENNA et al., 2018).

O Sítio Jaqueira Agroecologia possui trilhas que são utilizadas para visitações, uso para práticas de educação ambiental, pesquisas e contemplação da natureza (SILVA et al., 2012). Entre elas está a Trilha Interpretativa do Arroz, e como o próprio nome sugere, levava os visitantes ao plantio de arroz consorciado com a criação de peixes e marrecos, prática conhecida como Rizipiscicultura, uma técnica asiática, que consiste no plantio do arroz em água reservada nas caixas cheias, além da produção em conjunto de peixes e criação de marrecos nos tabuleiros, para realização do controle fitossanitário (SENNA et al., 2013). Nos dias atuais, essa técnica do sítio é utilizada para fins de resgate cultural e educação ambiental, sendo todo ano realizado esse plantio com a presença de pessoas engajadas pela busca do conhecimento ambiental e agroecológico (JUSTO, 2020).

As trilhas ecológicas surgem dentro da educação ambiental como um recurso metodológico, ou seja, uma prática ambiental, que visa à transmissão de conhecimentos através da visão, olfato e sentimentos tornando-se uma experiência direta com a realidade de forma interdisciplinar, possibilitando a consciência ambiental dos cidadãos (SILVA et al., 2012; JUSTO, 2020; SANTANA apud SOARES et al., 2020). A interpretação ambiental, por intermédio da trilha, busca informar e sensibilizar as pessoas para a compreensão da complexa temática ambiental e para o envolvimento em ações que promovam hábitos sustentáveis de uso dos recursos naturais (BEDIM, 2004).

A Associação Brasileira de Normas Técnicas (ABNT) normatiza as boas práticas e segurança na visitação de trilhas, e dispõem sobre as principais características dos usos em trilhas e a segurança durante seu percurso (ABNT, 2019).

O objetivo deste trabalho foi a classificar a Trilha Interpretativa do Arroz, localizada no Sítio Jaqueira Agroecologia localizado no município de Alegre/ES e sugerir a implantação de normas de segurança para a prática da educação ambiental. Como contribuição, este trabalho também visou aperfeiçoar os estudos realizados na trilha através da facilitação do acesso e da orientação de estudantes e outros visitantes durante a atividade. Também buscou contribuir como material de apoio a futuros trabalhos sobre o tema abordado. 


\section{MATERIAL E MÉTODO}

O Sítio Jaqueira Agroecologia está localizado sob as coordenadas geográficas $20^{\circ} 45^{\prime}$ 16,2" latitude e $-41^{\circ} 31^{\prime} 44,76^{\prime \prime}$ de longitude. O sítio se insere no município de Alegre, que possui uma área de $772 \mathrm{~km}^{2}$ e está organizado política e administrativamente em sete distritos: Anutiba, Araraí, Café, Celina, Rive, Santa Angélica e São João do Norte (PREFEITURA MUNICIPAL DE ALEGRE, 2020).

Com uma área total de 29,2 hectares, o Sítio Jaqueira Agroecologia possui topografia fortemente ondulada a montanhosa, intercalada por reduzidas áreas planas. O uso do solo teve início em 1920, sendo a ocupação do local iniciada após o desmatamento de toda área da propriedade para implantação da cafeicultura. Na década de 1960, a atividade agrícola deu lugar a pecuária, sendo cultivado pastagens para criação de gado de corte e muares, causando a degradação ambiental do local. A partir de 1983, o atual gestor da propriedade rural, Newton Barboza Campos, iniciou trabalhos de recuperação ambiental da propriedade. Atualmente o Sítio Jaqueira é reconhecido como propriedade rural modelo em gestão de recursos hídricos e pelo Sistema Agroflorestal (SAF) (SENNA et al., 2018).

Quanto as normas de segurança para implantação de Trilha Interpretativa, toda a descrição desta etapa metodológica atendeu os preceitos estabelecidos pela Norma Técnica Brasileira (NBR) 15505-2:2019 (ABNT, 2019). O percurso foi classificado conforme avaliação criteriosa do pesquisador, tendo como suporte a metodologia participativa (BRANDÃO apud BRANDÃO; STRECK, 2006). A classificação foi efetuada pela atividade específica de caminhada.

As tomadas de decisão que avaliaram o trajeto da Trilha Interpretativa do Arroz foram divididas nos seguintes aspectos:

Classificação: Conforme preconiza a NBR 15505-2:2019 (ABNT, 2019), a classificação é composta por quatro critérios:

a) severidade do meio: refere-se aos perigos e outras dificuldades decorrentes do meio natural, como temperatura, pluviosidade, riscos de quedas, facilidade de resgate, entre outros, que podem ser encontrados ao longo do percurso;

b) orientação no percurso: refere-se ao grau de dificuldade para orientação, como presença de sinalização, trilhas bem marcadas, presença de pontos de referência, entre outros, para completar o percurso;

c) condições do terreno: refere-se aos aspectos encontrados no percurso em relação ao piso e às condições para percorrê-lo, como tipos de pisos, trechos com obstáculos, trechos com pedras soltas, entre outros; 
d) intensidade de esforço físico: refere-se à quantidade de esforço físico requerido para cumprir o percurso, levando em conta extensão e desníveis (subidas e descidas), considerando um visitante comum.

Severidade do meio: a classificação para este critério, conforme estabelece a NBR 155052:2019 (ABNT, 2019), deve ser efetuada contando-se o número de ocorrências dos fatores listados abaixo, de forma cumulativa. Em cada trecho, cada fator foi contado uma vez somente, independentemente de sua probabilidade e presença em maior ou menor parte do percurso. Conforme indica a NBR 15505-2:2019, foram considerados os seguintes fatores:

a) exposição a desprendimentos espontâneos de pedras durante o percurso;

b) exposição a desprendimentos de pedras provocados pelo próprio grupo ou outro durante o percurso;

c) eventualidade de queda no vazio ou por um declive acentuado;

d) existência de passagens onde seja necessário o uso das mãos para progredir no percurso; exposição a trechos permanentemente escorregadios, pedregosos ou alagados durante o percurso; exposição a trechos escorregadios ou alagados devido às chuvas durante o percurso; travessia de rios ou outros corpos d'água com correnteza, a vau (sem ponte); alta probabilidade de chuvas intensas ou contínuas para o período;

i) alta probabilidade de que pela noite a temperatura caia abaixo de $0^{\circ} \mathrm{C}$;

j) alta probabilidade de que a temperatura caia abaixo de $5^{\circ} \mathrm{C}$ e a umidade relativa do ar supere os $90 \%$;

k) alta probabilidade de exposição a ventos fortes ou frios;

1) alta probabilidade de que a umidade relativa do ar seja inferior aos $30 \%$;

m) alta probabilidade de exposição ao calor em temperatura acima de $32^{\circ} \mathrm{C}$;

n) longos trechos de exposição ao sol forte;

o) tempo de realização da atividade igual ou superior a $1 \mathrm{~h}$ de marcha sem passar por um lugar habitado, um telefone de socorro (ou sinal de celular ou radiocomunicador) ou uma estrada aberta com fluxo de veículos;

p) tempo de realização da atividade igual ou superior a $3 \mathrm{~h}$ de marcha sem passar por um lugar habitado, um telefone de socorro (ou sinal de celular ou radiocomunicador) ou uma estrada aberta com fluxo de veículos;

q) a diferença entre o tempo necessário para completar o percurso e a quantidade de horas restantes de luz natural ao fim do dia (disponível na época do ano considerada) é menor que 3h; 
r) eventual diminuição da visibilidade por fenômenos atmosféricos que possa aumentar consideravelmente a dificuldade de orientação ou a localização de pessoas em algum trecho do percurso;

s) trajeto por vegetação densa ou por terreno irregular que possa dificultar a orientação ou a localização de pessoas em algum trecho do percurso;

t) região ou trechos sem acesso a água potável.

Após a análise das ocorrências, tendo como suporte a NBR 15505-2:2019 (ABNT, 2019), determinou-se a severidade do meio após a análise da "Trilha Interpretativa do Arroz" e a identificação do número de fatores correspondentes, conforme descreve a NBR 15505-2:2019 (Quadro 1).

Quadro 1 - Classificação segundo a severidade do meio

\begin{tabular}{|c|c|c|}
\hline Valor & Classificação & Número de fatores \\
\hline 1 & Pouco severo & Até 3 \\
\hline 2 & Moderadamente severo & 6 ou 5 \\
\hline 3 & Severo 8 \\
\hline 4 & Bastante severo & 9 a 12 \\
\hline 5 & Muito severo & Pelo menos 13 \\
\hline
\end{tabular}

Fonte: NBR 15505-2 (2019).

Orientação no percurso: considerando que o trajeto que determina a Trilha Interpretativa do Arroz já existe, a orientação do percurso foi avaliada a partir da classificação descrita na metodologia, cujos critérios foram efetuados avaliando-se as condições do terreno conforme descrito pela NBR 15505-2 (2019):

- No valor de atributo 1 é estabelecido a classificação de caminhos e cruzamentos bem definidos nas seguintes condições de orientação no percurso: caminhos principais bem delimitados ou sinalizados, com cruzamentos claros com indicação explícita ou implícita. Manter-se sobre o caminho não exige esforço de identificação do traçado. Eventualmente, pode ser necessário acompanhar uma linha marcada por um acidente geográfico inconfundível (por exemplo, uma praia ou uma margem de um lago).

- No valor de atributo 2 é estabelecido a classificação de caminho ou sinalização que indica a continuidade, nas seguintes condições de orientação no percurso: existe um traçado claro do caminho sobre o terreno ou sinalização para a continuidade do percurso. Requer atenção para a continuidade e o cruzamento de outros traçados, mas sem necessidade de uma interpretação precisa dos acidentes geográficos. Esta condição se aplica à maioria dos caminhos sinalizados que utilizam, em um mesmo percurso, distintos tipos de caminhos com numerosos cruzamentos como, por exemplo, trilhos de veículos automotores, trilhas para pedestres, caminhos para montaria, campos assinalados por marcos (bem localizados e bem mantidos). 
- No valor de atributo 3 é estabelecido a classificação que exige a identificação de acidentes geográficos e de pontos cardeais, nas seguintes condições de orientação no percurso: ainda que o itinerário se desenvolva por traçado sobre trilhas, percursos marcados por acidentes geográficos (rios, fundos de vales, costas, cristas, costões de pedras, entre outros) ou marcas de passagem de outras pessoas, a escolha do itinerário adequado depende do reconhecimento dos acidentes geográficos e dos pontos cardeais.

- No valor de atributo 4 é estabelecido a classificação que exige habilidades de navegação fora do traçado, nas seguintes condições de orientação no percurso: Não existe traçado sobre o terreno, nem segurança de contar com pontos de referência no horizonte. O itinerário depende da compreensão do terreno e do traçado de rumos.

- No valor de atributo 5 é estabelecido a classificação que exige navegação para utilizar trajetos alternativos e não conhecidos previamente, nas seguintes condições de orientação no percurso: O itinerário depende da compreensão do terreno e do traçado de rotas, além de exigir capacidade de navegação para completar o percurso. Os rumos do itinerário podem ser interrompidos inesperadamente por obstáculos que necessitem ser contornados.

Cada trecho deve ser avaliado em relação à dificuldade para percorrê-lo, uma vez que a classificação foi efetuada pela atividade específica de caminhada, no que se refere às condições do terreno, obstáculos e outras condições conforme preconiza a NBR 15505-2:2019.

Condições do terreno: a classificação para este critério foi efetuada avaliando-se as condições do terreno segundo o Quadro 2 Cada trecho foi avaliado em relação à difículdade para percorrê-lo, no que se refere às condições do terreno, obstáculos e outras condições (ABNT, 2019).

Quadro 2 - Classificação segundo as condições do terreno

\begin{tabular}{|c|c|c|}
\hline Valor & Classificação & Condições do terreno \\
\hline 1 & $\begin{array}{l}\text { Percurso em superfícies } \\
\text { planas }\end{array}$ & $\begin{array}{l}\text { Estradas e pistas para veículos, independentemente da sua inclinação. } \\
\text { Caminhos com degraus com piso plano e regular. Praias (de areia ou } \\
\text { de cascalho) com piso nivelado e firme. }\end{array}$ \\
\hline 2 & $\begin{array}{l}\text { Percurso por caminhos sem } \\
\text { obstáculos }\end{array}$ & $\begin{array}{l}\text { Caminhos por diversos terrenos firmes, mas que mantenham a } \\
\text { regularidade do piso, trilhas bem marcadas que não apresentem } \\
\text { grandes inclinações nem obstáculos que requeiram grande esforço } \\
\text { físico para serem ultrapassados. Percursos através de terrenos } \\
\text { uniformes como campos e pastagens não muito inclinados. }\end{array}$ \\
\hline 3 & $\begin{array}{l}\text { Percurso por trilhas } \\
\text { escalonadas ou terrenos } \\
\text { irregulares }\end{array}$ & $\begin{array}{l}\text { Percurso por trilhas com obstáculos ou degraus irregulares, de } \\
\text { tamanho, altura e inclinação diferentes. Percurso fora de trilhas e por } \\
\text { terrenos irregulares. Travessias de áreas pedregosas ou com } \\
\text { afloramentos rochosos (lajes de pedras). Trechos de pedras soltas, } \\
\text { pedreiras instáveis, raízes muito expostas, areões ou grandes erosões. }\end{array}$ \\
\hline 4 & Percurso com obstáculos & $\begin{array}{l}\text { Caminhos com obstáculos que podem exigir saltos ou a utilização das } \\
\text { mãos até I Sup. (graduação UIAA para escalada ou progressão } \\
\text { vertical). }\end{array}$ \\
\hline 5 & $\begin{array}{l}\text { Percurso que requer } \\
\text { técnicas verticais }\end{array}$ & $\begin{array}{l}\text { Trechos que exigem técnicas de escalada do grau II até III Sup. } \\
\text { (graduação UIAA para escalada ou progressão vertical). Exige a } \\
\text { utilização de equipamentos e técnicas específicas. }\end{array}$ \\
\hline
\end{tabular}

Fonte: NBR 15505-2 (2019)

Nucleus, v.18, n.1, abr. 2021 
Intensidade de esforço físico: cada trecho foi avaliado em relação à estimativa do esforço necessário, levando em conta a distância a ser percorrida e a influência dos desníveis (subidas e descidas). O cálculo da estimativa do esforço requerido foi efetuado utilizando o índice de esforço para caminhada em percursos de turismo (ABNT, 2019).

Para determinação do índice de esforço para caminhada em percursos de turismo, foi calculado considerando-se uma pessoa adulta, não-esportista e com bagagem leve, nas condições típicas de realização de caminhadas, com acréscimos decorrentes das condições do terreno e dos desníveis do percurso. O índice de esforço para caminhada em percursos de turismo foi ser expresso em horas conforme preconiza a NBR 15505-2:2019 (ABNT, 2019).

O tempo real para concluir o percurso pode variar em função de diversos fatores, como o condicionamento físico do caminhante, clima, ritmo de marcha, velocidade média, paradas, além dos mencionados acima (ABNT, 2019).

O índice de esforço para caminhada em percursos de turismo pode ser utilizado para comparações entre percursos distintos e para fornecer uma informação sistematizada e padronizada acerca da intensidade de esforço físico necessário para completar determinado percurso (ABNT, 2019).

O índice de esforço para caminhada em percursos de turismo é calculado, para trechos horizontais, a partir do cálculo do tempo de deslocamento horizontal obtido, dividindo-se a distância percorrida por uma velocidade média na horizontal conforme a equação abaixo:

$$
\mathbf{T}_{\mathrm{h}}=\mathbf{D}_{\mathrm{p}} / \mathrm{V}_{\mathrm{h}} \quad \text { Equação (1) }
$$

Th é o tempo de deslocamento na horizontal;

$D p$ é a distância percorrida no trecho; e

$V h$ é a velocidade média na horizontal.

As velocidades médias na horizontal a utilizar nesse cálculo são as apresentadas abaixo (NBR 15505-2:2019):

— piso fácil (por exemplo, estradas e pistas): $4 \mathrm{~km} / \mathrm{h}$;

— piso moderado (por exemplo, trilhas, caminhos lisos e prados): $3 \mathrm{~km} / \mathrm{h}$;

— piso difícil (por exemplo, caminhos ruins, pedregosos e leitos de rios): $2 \mathrm{~km} / \mathrm{h}$.

A influência do desnível é levada em conta calculando-se o tempo adicional devido aos desníveis (subidas ou descidas). Esse tempo representa um esforço adicional. É calculado utilizando-se o desnível dividido por uma velocidade vertical padrão (Quadro 3) (ABNT, 2019). Esses tempos adicionais para cada trecho devem ser calculados usando as equações abaixo:

$$
\text { Subida: } T_{s}=D / V_{S} \quad \text { Equação (2) }
$$




\section{Descida: $T_{d}=D / V_{d} \quad$ Equação (3)}

Onde:

$D$ é o desnível;

$V_{s}$ é a velocidade de deslocamento vertical em aclive;

$V_{d}$ é a velocidade de deslocamento vertical em declive;

$T_{s}$ é o tempo na subida;

$T_{d}$ é o tempo na descida.

Quadro 3 - Velocidades médias de deslocamento vertical em subida e em descida a considerar no cálculo de acréscimos de tempo para trechos com desnível na estimativa do esforço físico

\begin{tabular}{|c|c|}
\hline Tipo de inclinação & Velocidade média (caminhada) $\mathrm{m} / \mathrm{h}$ \\
\hline Subida (aclive) & 200 \\
\hline Descida (declive) & 300 \\
\hline
\end{tabular}

Fonte: NBR 15505-2 (2019).

Em cada trecho estimou-se dois tempos: o tempo correspondente ao deslocamento na horizontal e o tempo correspondente aos desníveis. Para a análise do percurso foram somados os tempos correspondentes a cada trecho, resultando um tempo total para o deslocamento na horizontal e um outro tempo total para os desníveis. O índice de esforço para caminhada em percursos de turismo é o resultado da soma do maior tempo obtido com a metade do menor tempo obtido (ABNT, 2019).

\section{IE $_{\text {ABNT }}:$ Maior T + (menor T) /2 Equação (4)}

Onde:

$I E A B N T$ é o índice de esforço para caminhada em percursos de turismo;

$T$ é o tempo, expresso em horas (h).

Classificação da Intensidade de esforço físico: a classificação para este critério foi efetuada estimando-se o esforço físico necessário para completar o percurso, em termos de duração da atividade, segundo o Quadro 4.

Quadro 4-Classificação segundo o índice de esforço para caminhada em percursos de turismo

\begin{tabular}{|c|c|c|}
\hline Valor & Classificação & $\begin{array}{c}\text { Estimativa de duração da atividade de caminhada } \\
(\mathrm{h})\end{array}$ \\
\hline 1 & Pouco esforço & Até 1 \\
\hline 2 & Esforço moderado & Mais de 1 e até 3 \\
\hline 3 & Esforço significativo & Mais de 3 e até 6 \\
\hline 4 & Esforço intenso & Mais de 6 e até 10 \\
\hline 5 & Esforço extraordinário & Mais de 10 \\
\hline
\end{tabular}

Fonte: NBR 15505-2 (2019).

Comunicação da classificação: após percorrer o trajeto, o valor obtido na avaliação definiu-se a comunicação da classificação. O sistema de comunicação que foi fornecido visou expressar as exigências técnicas e físicas para a realização da visitação à Trilha Interpretativa do Arroz. 
A simbologia da descrição foi mostrada na Figura 1. A comunicação da classificação do percurso deve apresentar os quatro critérios de forma unificada, com o resultado de cada critério associado ao símbolo respectivo.

Figura 1 - Referência da classificação do percurso

\begin{tabular}{|c|c|}
\hline Critério de percurso & Classificaçâo \\
\hline Severidade do meio & $\begin{array}{l}1 \text { - Pouco severo } \\
2 \text { - Moderadamente severo } \\
3 \text { - Severo } \\
4 \text { - Bastante severo } \\
5 \text { - Muito severo }\end{array}$ \\
\hline Orientaçăo & $\begin{array}{l}1 \text { - Caminhos e cruzamentos bem definidos } \\
2 \text { - Caminho ou sinalização que indica continuidade } \\
3 \text { - Exige a identificação de acidentes geográficos e de pontos cardeais } \\
4 \text { - Exige habilidades de navegaçăo fora do traçado } \\
5 \text { - Exige navegação para utilizar trajetos alternativos e não conhecidos } \\
\text { previamente }\end{array}$ \\
\hline Condiçóes do terreno & $\begin{array}{l}1 \text { - Percurso em superfícies planas } \\
2 \text { - Percurso por caminhos sem obstáculos } \\
3 \text { - Percurso por trilhas escalonadas ou terrenos irregulares } \\
4 \text { - Percurso com obstáculos } \\
5 \text { - Percurso que requer técnicas verticais }\end{array}$ \\
\hline Intensidade de esforço físico & $\begin{array}{l}1 \text { - Pouco esforço } \\
2 \text { - Esforço moderado } \\
3 \text { - Esforço significativo } \\
4 \text { - Esforço intenso } \\
5 \text { - Esforço extraordinário }\end{array}$ \\
\hline
\end{tabular}

Fonte: Adaptado de NBR 15505-2 (2019)

Conforme preconiza a NBR 15505-2:2019 as placas confeccionadas devem apresentar as seguintes informações: a) local de início e local de chegada; b) desnível total de subida; c) desnível total de descida; d) distância total; e) condições específicas relevantes (como, por exemplo, percursos autoguiados, chuvas, época do ano, áreas alagadas, entre outros) (ABNT, 2019).

A NBR 15505-2:2019 recomenda que a comunicação da classificação esteja disponível no início do percurso ou em locais de acesso público. Destaca-se que, metodologicamente, a comunicação da classificação deve ser atualizada sempre que houver alterações nas condições gerais do percurso (ABNT, 2019).

Durante o período de pandemia SARS-CoV-2 ou Covid-19 (Organização Mundial da Saúde, 2020) o Sítio Jaqueira Agroecologia esteve fechado para visitação. Desta forma, a análise dos parâmetros de segurança para visitação a Trilha Interpretativa do Arroz, conforme preconiza a NBR 15505-2:2019, se deu através de registros fotográficos, manuscritos e apontamentos detalhados estabelecidos por meio de diário de bordo durante as visitações dos autores a trilha, além de sua expertise. 
Metodologicamente, esta pesquisa foi classificada como qualitativa, devido ao subjetivismo empregado. Além disto, é a mais adequada para descrever fenômenos turísticos (MAZUCATO apud SOARES et al., 2018). Também se recorreu a pesquisa de campo exploratória-descritiva devido ao uso de recurso visual e diário de campo. A pesquisa descrita se caracteriza por ser aquela aonde o pesquisador procura conhecer e interpretar a realidade, sem nela interferir para modifica-la (FONTANA apud SOARES et al., 2018).

\section{RESULTADO E DISCUSSÃO}

A aplicação de normas de segurança propostas por meio da NBR 15505-2:2019 fornece a Trilha Interpretativa do Arroz uma adequação que atende à norma estabelecida pela associação brasileira de normas técnicas (ABNT). A percepção de segurança investigada durante a visitação a trilha permitiu verificar as exigências relacionadas a público visitante, as descrições que tratam da severidade, orientação, condições do terreno e intensidade de esforço, conforme preconizado pela referida NBR.

Foi possível apontar neste trabalho mediante a análise do material inventariado e a experiência dos autores, os perigos e riscos para o percurso da Trilha Interpretativa do Arroz, sendo estes os seguintes:

a) quedas de galhos durante o percurso;

b) quedas devido a possibilidade de o piso ficar escorregadio durante o período chuvoso (lama) e na travessia entre os campos inundados aonde se cultivava o arroz;

c) possibilidade de ataque aos visitantes por animais peçonhentos e himenópteras (abelhas, zangões e maribondos); e

d) mal estar dos visitantes devido à alta sensação térmica comum ao município de Alegre nos meses quentes, já que a temperatura máxima anual (média) é de $29^{\circ} \mathrm{C}$ (PREFEITURA MUNICIPAL DE ALEGRE, 2020).

Destaca-se que, normativamente, a identificação de perigos e riscos deve ser revisada anualmente, bem como as propostas de criação de um plano para o seu enfrentamento. Quanto aos demais critérios utilizados na classificação da Trilha Interpretativa do Arroz, verificaram-se:

a) A classificação da severidade do meio, após análise de ocorrências dos fatores descritos na NBR, tipifica a Trilha Interpretativa do Arroz como de pouca severidade, por apresentar de forma cumulativa em seu trecho os fatores "alta probabilidade de exposição ao calor em temperatura acima de $32{ }^{\circ} \mathrm{C}$ " e "exposição a trechos permanentemente escorregadios, pedregosos ou alagados durante o percurso". 
b) Quanto a orientação do percurso, é possível classificá-lo como o valor 1, que representa caminhos e cruzamentos definidos. Esta tipificação é condizente com o verificado durante a visitação, já que a Trilha Interpretativa do Arroz não exige identificação do traçado, pois, os caminhos principais são bem delimitados.

c) Após a análise das condições do terreno onde se dá o trajeto da Trilha Interpretativa do Arroz, verificou-se em termos de dificuldade para percorrê-la a classificação como um percurso por caminhos sem obstáculos, cujo valor é 2. Esta classificação se deve a ocorrência de pequenos obstáculos que requer pouco esforço, tais como pequenas inclinações. A maior parte do terreno pode ser considerada uniforme.

d) Conforme descreve a NBR 15505-2 (2019) a determinação da intensidade de esforço físico se dá em função do tempo que é necessário para que um visitante adulto, não-esportista e com bagagem leve, executando um deslocamento em condições normais de caminhada, utiliza para percorrer todo o trajeto que compõe a Trilha Interpretativa do Arroz. Desta forma, verificouse que o índice de esforço para caminhada em percursos de turismo (IE ABNT) para a Trilha Interpretativa do Arroz é igual a IE ABNT de 1,5h, sendo classificado como esforço moderado (valor 2).

A classificação de trilhas conforme preconiza a NBR 15505-2:2019 são de fácil aplicação já que apenas refletem indicações que devem ser observadas e a elas atribuídas algum valor metodologicamente simbólico.

Devido a pandemia de Covid-19 o Sítio Jaqueira Agroecologia está fechado para visitação, fato que impediu a instalação da placa designando a segurança da Trilha Interpretativa do Arroz. No entanto, é importante destacar que, caso fosse possível, a placa ficaria disponível no início do percurso, de modo que prepare o visitante para o trajeto, respeitando-se o que indica a NBR 15505-2 (2019).

\section{CONSIDERAÇÕES FINAIS}

O Sítio Jaqueira Agroecologia destaca-se regionalmente no âmbito da agroecologia pelo seu destaque no uso de práticas sustentáveis e ecologicamente responsáveis. Sua contribuição ao ambiente faz com que esta propriedade ganhe importância como fonte de informação para aqueles que recorrem à visitação das atividades realizadas neste local.

Destaca-se quanto à segurança dos visitantes que a investigação crítica ao trajeto da Trilha Interpretativa do Arroz, tendo como suporte teórico as determinações estabelecidas na NBR 15505-2:2019, que seu percurso pode ser classificado como seguro, fato que poderá ser constatado através da placa indicadora de segurança. A placa permitirá ao Senhor Newton 
Campos aos visitantes uma visita aonde todos os sentidos estejam voltados para a experiência na visitação, já que a segurança permite esta dedicação.

Diante do exposto, este trabalho pretende contribuir com a agroecologia através dos indivíduos que buscam suporte teórico e prático quanto ao estabelecimento de trilhas interpretativas, permitindo uma visão geral das potencialidades que se espera de uma propriedade agroecológica e dos requisitos de segurança necessários para uma prática segura da visitação.

\section{REFERÊNCIAS}

ABNT NBR 15505-2. Turismo com atividades de caminhada - Parte 2: Classificação para percursos. Rio de Janeiro, 14 p., 2019. Disponível em: https://tinyurl.com/yyanugbl. Acesso em: 06 mai. 2020.

BEDIM, B. P. Trilhas interpretativas como instrumento pedagógico para a educação biológica e ambiental: reflexões. Anais... BioEd, 2004.

BRANDÃO, C. R. A Pesquisa Participante e a partilha do saber: uma introdução. In: BRANDÃO, C. R.; STRECK, D. R. Pesquisa Participante: o saber da partilha. Aparecida: Ideias \& Letras, 2006.

FONTANA, F. Técnicas de pesquisa. In. SOARES, A. G.; TAUIL, C. E.; DONZELLI, C. A.; FONTANA, F.; MAZUCATO, T. P. DA S.; CHOTOLLI, W. P. (Org.) Metodologia da pesquisa e do trabalho científico. Penápolis: FUNEPE, 2018.

JUSTO, M. G. Agroecologia e agricultura urbana na cidade de São Paulo: movimentos socioespaciais e socioterritoriais. Rev. NERA, Presidente Prudente v. 23, n. 55, pp. 218-242 Set.Dez./2020.

MAZUCATO, T. P. DA S. Métodos. In. SOARES, A. G.; TAUIL, C. E.; DONZELLI, C. A.; FONTANA, F.; MAZUCATO, T. P. DA S.; CHOTOLLI, W. P. (Org.) Metodologia da pesquisa e do trabalho científico. Penápolis: FUNEPE, 2018.

ORGANIZAÇÃO MUNDIAL DA SAÚDE. Pandemia da doença de Coronavírus (COVID19). 2020. Disponível em: $<$ https://www.who.int/emergencies/diseases/novel-coronavirus2019/advice-for-public>. Acesso em: 29 mai. 2020.

PREFEITURA MUNICIPAL DE ALEGRE. Características geográficas. 2020. Disponível em: https://alegre.es.gov.br/site/index.php/a-cidade/historia/caracteristicas-geograficas. Acessado em: 06 mai. 2020.

SANTANA, S. DE O. Ambientes restauradores como cuidado de saúde: contribuições da psicologia ambiental durante o contexto da pandemia de Covid-19. In: SOARES, M. J. N.; SILVA, D. S. DA, C.; SANTOS, S. B. DOS; SOUZA, A. B.; DANTAS, J. O. (org.). Educação ambiental e a pandemia do novo coronavírus: abordagens interdisciplinares. Aracaju: Criação, 2020. 
SENNA, D. S.; KOBI, H. B.; SANTOS, R. A. B.; SOUZA, D. S.de; MARTINS, K. G. G.; MEIRA, A. C. H. "Plantadores de Água": uma experiência de construção coletiva de saberes agroecológicos. Cadernos de Agroecologia, v. 8, n. 2, 2013.

SENNA, D. S.; MONTEIRO, R.; KOBI, H.; AZEVEDO, P.; SILVA, A. Análise da estrutura do sistema agroflorestal no Sítio Jaqueira, Alegre, ES. Cadernos de Agroecologia, v. 13, n. 1, 2018.

SILVA, M. M. DA.; NETTO, T. A.; AZEVEDO, L. F. DE.; SCARTON, L. P.; HILLIG, C. Trilha ecológica como prática de educação ambiental. Revista Eletrônica em Gestão, Educação e Tecnologia Ambiental REGET/UFSM. v 5, n. 5, p. 705 - 719, 2012. 